\title{
Zingiber mioga (Thunb.) Roscoe attenuates allergic asthma induced by ovalbumin challenge
}

\author{
NA-RAE SHIN ${ }^{1,2}$, IN-SIK SHIN ${ }^{1,3}$, CHAN-MI JEON ${ }^{1,4}$, JU-MI HONG $^{1,5}$, OK-KYOUNG KWON ${ }^{1}$, \\ HUI-SEONG KIM ${ }^{1}$, SEI-RYANG OH ${ }^{1}$, KYU-WOUNG HAHN ${ }^{2}$ and KYUNG-SEOP AHN ${ }^{1}$ \\ ${ }^{1}$ Natural Medicine Research Center, Korea Research Institute of Bioscience and Biotechnology, Cheongwon-Gun, \\ Chungbuk 363-883; ${ }^{2}$ Department of Biological Science and Biotechnology, Hannam University, Yuesong-Gu, \\ Daejeon 305-811; ${ }^{3}$ College of Veterinary Medicine, Chonnam National University, Buk-Gu, Gwang-Ju 500-757; \\ ${ }^{4}$ College of Pharmacy, Chungnam National University, Yuesong-Gu, Daejeon 305-764; ${ }^{5}$ College of Pharmacy, \\ Chungbuk National University, Cheongju, Chungbuk 361-763, Republic of Korea
}

Received June 18, 2014; Accepted March 5, 2015

DOI: $10.3892 / \mathrm{mmr} .2015 .3914$

\begin{abstract}
Zingiber mioga (Thunb.) Roscoe (ZM) is a traditional medicine, used to treat inflammatory diseases. The present study aimed to evaluate the inhibitory effects of ZM on the inflammatory response in lipopolysaccharide (LPS)-stimulated RAW264.7 murine macrophage cells and in a mouse model of ovalbumin (OVA)-induced allergic asthma. Mice received OVA sensitization on day 0 and 14, and were challenged with OVA between days 21 and 23. ZM was administered to the mice at a dose of $30 \mathrm{mg} / \mathrm{kg}, 1 \mathrm{~h}$ prior to OVA challenge. In LPS-stimulated RAW264.7 cells, ZM significantly decreased nitric oxide (NO) and tumor necrosis factor (TNF)- $\alpha$ production in a concentration-dependent manner, and mRNA expression of inducible NO synthase (iNOS), TNF- $\alpha$ and matrix metalloproteinase (MMP)-9 was reduced. In addition, treatment with ZM decreased the inflammatory cell count in bronchoalveolar lavage fluid from the mice, and reduced the expression of interleukin (IL)-4, IL-5, IL-13, eotaxin and immunoglobulin E. ZM also reduced airway hyperresponsiveness in OVA-challenged mice, and attenuated the infiltration of inflammatory cells and mucus production in the airways, with a decrease in the expression of iNOS and MMP-9 in lung tissue. In conclusion, the results of the present study indicate that ZM effectively inhibits inflammatory
\end{abstract}

Correspondence to: Professor Kyu-Woung Hahn, Department of Biological Science and Biotechnology, Hannam University, 1646 Yuseong-Daero, Yuseong-Gu, Daejeon 305-811, Republic of Korea

E-mail: hahnkw@hnu.kr

DrKyung-Seop Ahn, Natural Medicine Research Center, Korea Research Institute of Bioscience and Biotechnology, 30 Yeongudanji-road, Ochang-Eup, Cheongwon-Gun, Chungbuk 363-883, Republic of Korea E-mail: ksahn@kribb.re.kr

Key words: Zingiber mioga (Thunb.) Roscoe, allergic asthma, inflammatory disease, inflammatory mediator responses. Therefore, it may be that $\mathrm{ZM}$ has potential as a therapeutic agent for use in inflammatory diseases.

\section{Introduction}

Allergic asthma is a chronic respiratory disease, the prevalence of which is increasing rapidly worldwide (1). The characteristic pathophysiological features of asthma include chronic eosinophilic inflammation of the airways, airway hyperresponsiveness (AHR) and eventual progression to airway remodeling (1). Nitric oxide (NO) is derived from inducible NO synthase (iNOS), and has a crucial role in airway inflammation (2). The development of allergic asthma is associated with overexpression of iNOS in the airways, which results in an asthmatic response. Previous studies have demonstrated that iNOS expression is associated with the induced activation of T-helper (Th)2 lymphocytes, which results in the pathophysiological alterations that occur in asthma $(2,3)$. Th2 lymphocytes produce various Th2 cytokines that have important roles in the development of allergic asthma (3). Th2 cytokines include interleukin (IL)-4, IL-5 and IL-13, and induce secretion of allergen-specific immunoglobulin (Ig) E, chemokines and eosinophils, as well as mucus production. Chemokines, such as eotaxin, are essential for the delivery of eosinophils to the airways (4). Matrix metalloproteinase 9 (MMP-9) is also associated with the development of allergic asthma. MMP-9 belongs to a family of extracellular proteases that are responsible for the degradation of the extracellular matrix during tissue remodeling (5). MMP-9 in particular appears to have an important role in chronic airway inflammation and remodeling in asthma, and was shown to be upregulated in a murine asthma model in association with an accumulation of inflammatory cells (6). The suppression of NO production and MMP-9 expression is an important therapeutic target for asthma.

Zingiber mioga (Thunb.) Roscoe (ZM) is a medicinal herb belonging to the Mioga family. ZM is globally used to treat inflammatory diseases, including stomatitis (7). In addition to their extensive use as spices, numerous types of ginger have been used in traditional Oriental medicine in order to 
ameliorate symptoms, such as inflammation, rheumatic disorders and gastrointestinal discomforts (7). Previous studies have demonstrated that ZM exhibits anti-inflammatory, anticancer and antioxidant effects in vitro $(7,8)$. Kim et al $(8)$ previously showed that ZM was able to inhibit the production of inflammatory mediators in lipopolysaccharide (LPS)-stimulated macrophage cells. However, to the best of our knowledge, no study has investigated the protective effects of ZM on airway inflammation in an OVA-induced allergic asthma model.

The present study aimed to investigate the inhibitory potential of ZM on airway inflammation in asthma, using a murine model of OVA-induced asthma and LPS-stimulated RAW264.7 cells. In order to investigate the possible mechanism underlying the effects of ZM, the abundance of pro-inflammatory proteins in lung tissue was examined, as well as the expression of mRNA in RAW264.7 cells.

\section{Materials and methods}

Cell culture and cell viability. The RAW264.7 murine macrophage cells (American Type Tissue Collection, Manassas, VA, USA) were maintained in Dulbecco's modified Eagle's medium (DMEM; Gibco Life Technologies, Grand Island, NY, USA), supplemented with $10 \%$ heat-inactivated fetal bovine serum (FBS; Gibco Life Technologies) and antibiotics (100 U/ml penicillin, $100 \mu \mathrm{g} / \mathrm{ml}$ streptomycin, Gibco Life Technologies) at $37^{\circ} \mathrm{C}$ in an incubator containing $5 \%$ $\mathrm{CO}_{2}$ and $95 \%$ air. The cell viability of cells treated with $\mathrm{ZM}$ was measured using a 3-(4,5-dimethylthiazol-2-yl)-2,5-diphenyltetrazolium bromide (MTT; Amresco, LLC, Solon, OH, USA) assay. The RAW264.7 cells were cultured in 96-well plates at a density of $1 \times 10^{4}$ cells/well. The ZM extract was obtained from The Plant Extract Bank at the Korea Research Institute of Bioscience and Biotechnology (PB2176.2; Chungbuk, Korea). The ZM extract was added to each individual well at a concentration of 20,40,80 and $100 \mu \mathrm{g} / \mathrm{ml}$, and then incubated for $24 \mathrm{~h}$. The control cells were treated with an equivalent volume of phosphate-buffered saline (PBS; pH 7.4). MTT solution (10 $\mu \mathrm{l})$ was added to each well, and the plates were incubated for $4 \mathrm{~h}$ at $37^{\circ} \mathrm{C}$. After 4 h, $100 \mu$ l dimethyl sulfoxide (Samchun Pure Chemical Co., Ltd., Daejeon, Korea) was added to each well to solubilize the formazan crystals. The optical density was measured at $570 \mathrm{~nm}$ using a microplate reader (VersaMax; Molecular Devices, Sunnyvale, CA, USA).

Determination of NO production. The cells $\left(5 \times 10^{4}\right.$ cells/well) were seeded in 96-well plates in FBS-free DMEM, and were treated with various concentrations of ZM (10, 20 and $40 \mu \mathrm{g} / \mathrm{ml}$ ) for $1 \mathrm{~h}$. Subsequently, the cells were incubated in the presence of LPS $(0.5 \mu \mathrm{g} / \mathrm{ml})$ for $24 \mathrm{~h}$. The nitrite accumulation in the culture medium was measured using Griess reagent (Promega Corporation, Madison, WI, USA). The absorbance was then measured at $540 \mathrm{~nm}$ using a microplate reader (iMark Microplate absorbance reader; Bio-Rad Laboratories, Inc. Hercules, CA, USA).

Determination of pro-inflammatory cytokines. Cells were treated as described above, and the concentration of tumor necrosis factor- $\alpha$ (TNF- $\alpha$ ) was quantified in the culture medium, using a competitive enzyme-linked immunosorbent assay (ELISA) kit (BD Biosciences, San Jose, CA, USA), according to the manufacturer's instructions. The absorbance was measured at $450 \mathrm{~nm}$ in a microplate reader (Bio-Rad Laboratories, Inc.). The absolute concentrations were obtained by running standard curves on the identical ELISA plates.

Reverse transcriptase-polymerase chain reaction (RT-PCR). Total RNA was extracted from the cells using TRIzol ${ }^{\circledR}$ reagent (Life Technologies, Carlsbad, CA, USA). For RT-PCR, single-strand cDNA (Qiagen, Hilden, Germany) was synthesized from $2 \mu \mathrm{g}$ total RNA using a commercial PCR kit (166-2600EDU; Bio-Rad Laboratories Inc.) and a T100 thermal cycler (186-1096; Bio-Rad Laboratories Inc.). The primer sequences used in the PCR were as follows: Forward: 5'-CAAGAGTTTGACCAGAGGACC-3', and reverse: 5'-TGGAACCACTCGTACTTGGGA-3' for iNOS, forward: 5'-AAGCACATGCAGAATGAGTACCG-3' and reverse: 5'-GTGGGACAGCTTCTGGTCGAT-3' for MMP-9 and forward: 5'-CGCTCATTGCCGATAGTGAT-3' and reverse: 5'-TGTTTGAGACCTTCAACACC-3' for $\beta$-actin (Bioneer, Daejeon, Korea). The following cycle conditions were set for each PCR reaction: iNOS, forward, $95^{\circ} \mathrm{C}$ for $5 \mathrm{~min}$, then $94^{\circ} \mathrm{C}$ for $30 \mathrm{sec}, 58^{\circ} \mathrm{C}$ for $30 \mathrm{sec}$ and $72^{\circ} \mathrm{C}$ for $45 \mathrm{sec}$ for 32 cycles, and a final extension step at $72^{\circ} \mathrm{C}$ for $5 \mathrm{~min}$; MMP-9 and $\beta$-actin, forward, $94^{\circ} \mathrm{C}$ for $5 \mathrm{~min}$, then $94^{\circ} \mathrm{C}$ for $30 \mathrm{sec}, 50^{\circ} \mathrm{C}$ for $30 \mathrm{sec}$ and $72^{\circ} \mathrm{C}$ for $45 \mathrm{sec}$ for 30 cycles, and a final extension step at $72^{\circ} \mathrm{C}$ for $10 \mathrm{~min}$. The PCR products were then subjected to $1.5 \%$ agarose gel electrophoresis and were stained with $5 \mu \mathrm{g} / \mathrm{ml}$ ethidium bromide (Bio-Rad Laboratories Inc.). Images were captured using an Olympus C4000 zoom camera system (Olympus America Inc., Center Valley, PA, USA)

Mice. Specific pathogen-free female BALB/c mice (19-21 g, 6-8 weeks-old) were obtained from Koatech Co. (Pyeongtaek, Korea). The 28 mice were housed under standard conditions (temperature, $22 \pm 2^{\circ} \mathrm{C}$; humidity, $55 \pm 5 \%$; 12 h-light/dark cycle) with food and water. All of the experimental procedures were approved by the Institutional Animal Care and Use Committee of the Korea Research Institute of Bioscience and Biotechnology.

Induction of asthma in BALB/c mice and drug administration. The mice were divided into four groups $(n=7)$ : Normal control, PBS sensitization/challenge; OVA, OVA sensitization/challenge + PBS; Mon, OVA sensitization/challenge + montelukast $(30 \mathrm{mg} / \mathrm{kg}$; Sigma-Aldrich, St. Louis, MO, USA); ZM, OVA sensitization/challenge $+\mathrm{ZM}(30 \mathrm{mg} / \mathrm{kg})$. Airway inflammation was induced by an OVA (Sigma-Aldrich) challenge. Each mouse was immunized by an intraperitoneal injection of $20 \mu \mathrm{g}$ OVA, emulsified with $2 \mathrm{mg}$ aluminum hydroxide (Thermo Fisher Scientific, Waltham, MA, USA) in $200 \mu \mathrm{l}$ PBS (pH 7.4), on days 0 and 14. On days 21, 22 and 23 the mice were exposed, by inhalation, to $1 \%$ (w/v) OVA aerosolized solution using an ultrasonic nebulizer (NE-U12; Omron Corp., Tokyo, Japan) for $1 \mathrm{~h}$. The ZM groups of asthma-induced mice were treated orally with $30 \mathrm{mg} / \mathrm{kg} \mathrm{ZM}$, or with an oral injection of $30 \mathrm{mg} / \mathrm{kg}$ montelukast $1 \mathrm{~h}$ prior to the OVA challenge. Montelukast is a cysteinyl leukotriene (cys-LT)-1 


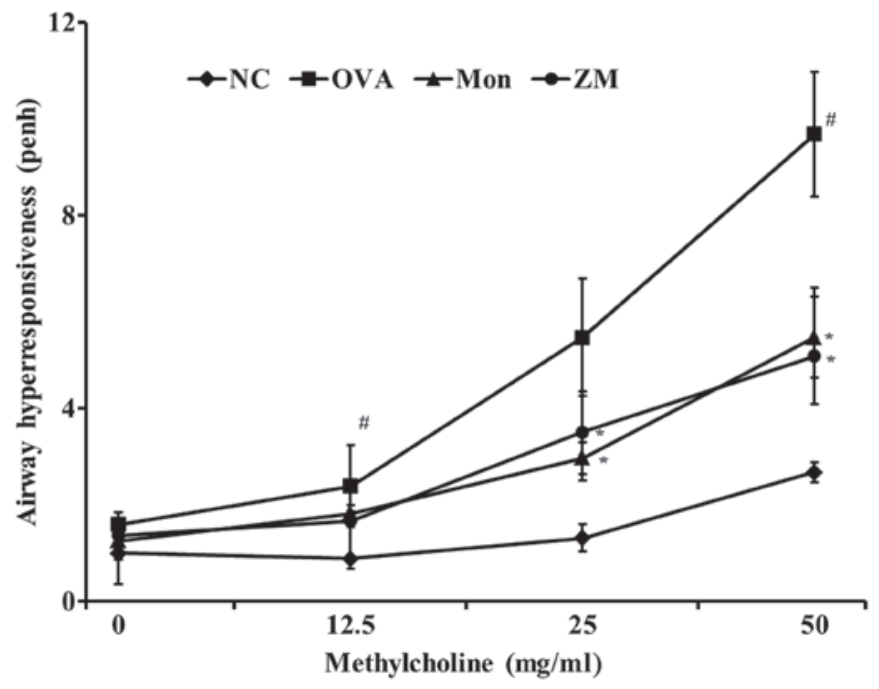

Figure 1. ZM reduced airway hyperresponsiveness in OVA-challenged mice. Airway hyperresponsiveness was examined $24 \mathrm{~h}$ following the final challenge of mice with various concentrations of methylcholine $(12.5,25$ or $50 \mathrm{mg} / \mathrm{ml})$, using single-chamber whole body plethysmography. Data are expressed as the mean \pm standard deviation ( $\mathrm{n}=7$ /group). ${ }^{~} \mathrm{P}<0.05$, compared with $\mathrm{NC}$ and ${ }^{*} \mathrm{P}<0.05$, compared with OVA. NC, normal control mice; OVA, ovalbumin-challenged mice; Mon, montelukast (30 mg/kg) + OVA-challenged mice; ZM, Zingiber mioga (Thunb.) Roscoe (30 mg/kg) + OVA-challenged mice. NC, normal control.

receptor agonist, and was used as a positive control in the present study. The control mice were treated orally with an equivalent volume of PBS.

Measurement of AHR. A total of 24 hours after the final aerosol challenge, AHR was measured indirectly using single-chamber whole body plethysmography (Allmedicus, Seoul, Korea) following exposure to aerosolized PBS, followed by aerosols containing increasing concentrations of methacholine (12.5, 25 and $50 \mathrm{mg} / \mathrm{ml}$; Sigma-Aldrich) in PBS, for $3 \mathrm{~min}$ at each exposure level.

Collection of bronchoalveolar lavage fluid (BALF) and serum. For collection of BALF, the mice were sacrificed $24 \mathrm{~h}$ after AHR measurement with an intraperitoneal injection of phenobarbital (50 mg/kg; Hanlim Pharm., Co., Ltd., Seoul, Korea), and tracheotomy was performed as described previously (9). The lung was lavaged three times, and each time, fluid was withdrawn via the trachea with $0.5 \mathrm{ml}$ PBS (total volume, $1.5 \mathrm{ml}$ ). The number of inflammatory cells was determined by counting the cells in $\geq 5$ squares of a hemocytometer (Marienfeld, Lauda-Königshofen, Germany), following exclusion of the dead cells by Trypan blue (Sigma-Aldrich) staining. The differential cell count of the BALF was performed using Diff-Quik ${ }^{\circledR}$ staining reagent (B4132-1A; IMEB Inc., San Marcos, CA, USA), according to the manufacturer's instructions. The blood was collected from the inferior vena cava and centrifuged at $200 \mathrm{x}$ g for $10 \mathrm{~min}$ at $4^{\circ} \mathrm{C}$. The supernatant was then stored at $-70^{\circ} \mathrm{C}$ until further use.

Measurement of immunoglobulin (Ig)E in serum and cytokines in BALF. The Th2 cytokines (IL-4, IL-5, IL-13) and eotaxin in BALF were measured using Mouse IL-4, IL-5 and IL-13 Quantikine ELISA kits (R\&D Systems, Minneapolis, MN, USA), according to the manufacturer's instructions. The total $\operatorname{IgE}$ and OVA-specific IgE serum levels were measured by ELISA. Briefly, microtiter plates were coated with
anti-IgE antibodies (anti-mouse IgE; $10 \mathrm{~g} / \mathrm{ml}$; AbD Serotec, Oxford, UK) in PBS-Tween 20, and incubated with BALF or plasma samples. The plates were then washed four times with washing solution (contained in ELISA kits), and $200 \mu \mathrm{l}$ o-phenylenediamine dihydrochloride (Sigma-Aldrich) was added to each well. The plates were incubated for $10 \mathrm{~min}$ in the dark and the absorbance was measured at $450 \mathrm{~nm}$ using the iMark microplate absorbance reader.

Immunoblotting. The mouse lung tissue was homogenized (1/10 w/v) in Tissue Lysis/Extraction reagent (Sigma-Aldrich) that contained a protease inhibitor cocktail (Sigma-Aldrich) using a homogenizer (IKA, Guangzhou, China). In order to extract the nuclear protein, the lung tissue was homogenized using an extraction kit (Thermo Fisher Scientific). The protein concentrations of the samples were determined using Bradford reagent (Bio-Rad Laboratories, Inc.). Equal quantities of total protein $(30 \mu \mathrm{g})$ were separated by $10 \%$ SDS-polyacrylamide gel electrophoresis and transferred onto a polyvinylidene fluoride membrane (IPVH00010; Merck Millipore, Damstadt, Germany). The membranes were then incubated with blocking solution ( $5 \%$ non-fat milk), followed by an overnight incubation at $4^{\circ} \mathrm{C}$ with the appropriate primary antibodies. The following primary antibodies and dilutions were used: Rabbit monoclonal anti- $\beta$-actin $(1: 2,000$ dilution; cat. no. P60709; Cell Signaling Technologies, Inc., Danvers, MA, USA); rabbit polyclonal anti-iNOS (1:1,000 dilution; cat. no. ADI-KAS-NO001-F; Enzo Life Sciences Inc., Farmingdale, NY, USA) and rabbit polyclonal anti-MMP-9 (1:1,000 dilution; cat. no. ab38898; Cell Signaling Technologies, Inc.). The blots were washed three times with tris-buffered saline containing Tween-20 (TBST; Biosesang, Seongnam, Korea) and then incubated with a 1:10,000 dilution of horseradish peroxidase (HRP)-conjugated secondary antibody (cat. no. 211-542-171; Jackson ImmunoResearch Laboratories, Inc., West Grove, PA, USA) for $30 \mathrm{~min}$ at room temperature. The blots were washed a further three 


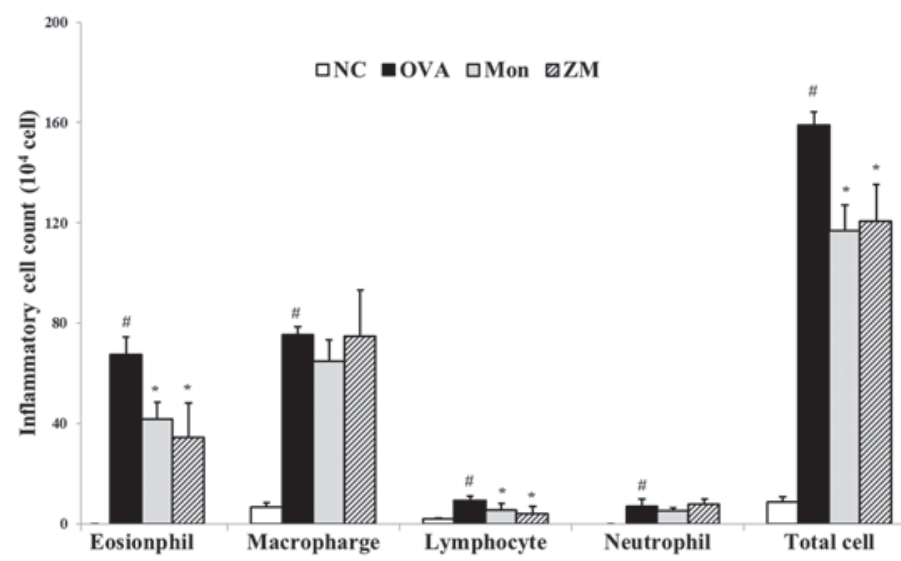

Figure 2. ZM inhibited the number of inflammatory cells in the bronchoalveolar lavage fluid of the mice. The cells were isolated by centrifugation and stained with Diff-Quik stain reagent. Data are expressed as the mean \pm standard deviation ( $\mathrm{n}=7 /$ group). ${ }^{~} \mathrm{P}<0.05$, compared with NC and ${ }^{*} \mathrm{P}<0.05$, compared with OVA. $\mathrm{NC}$, normal control mice; OVA, ovalbumin-challenged mice; Mon, montelukast (30 mg/kg) + OVA-challenged mice; ZM, Zingiber mioga (Thunb.) Roscoe $(30 \mathrm{mg} / \mathrm{kg})+$ OVA-challenged mice.
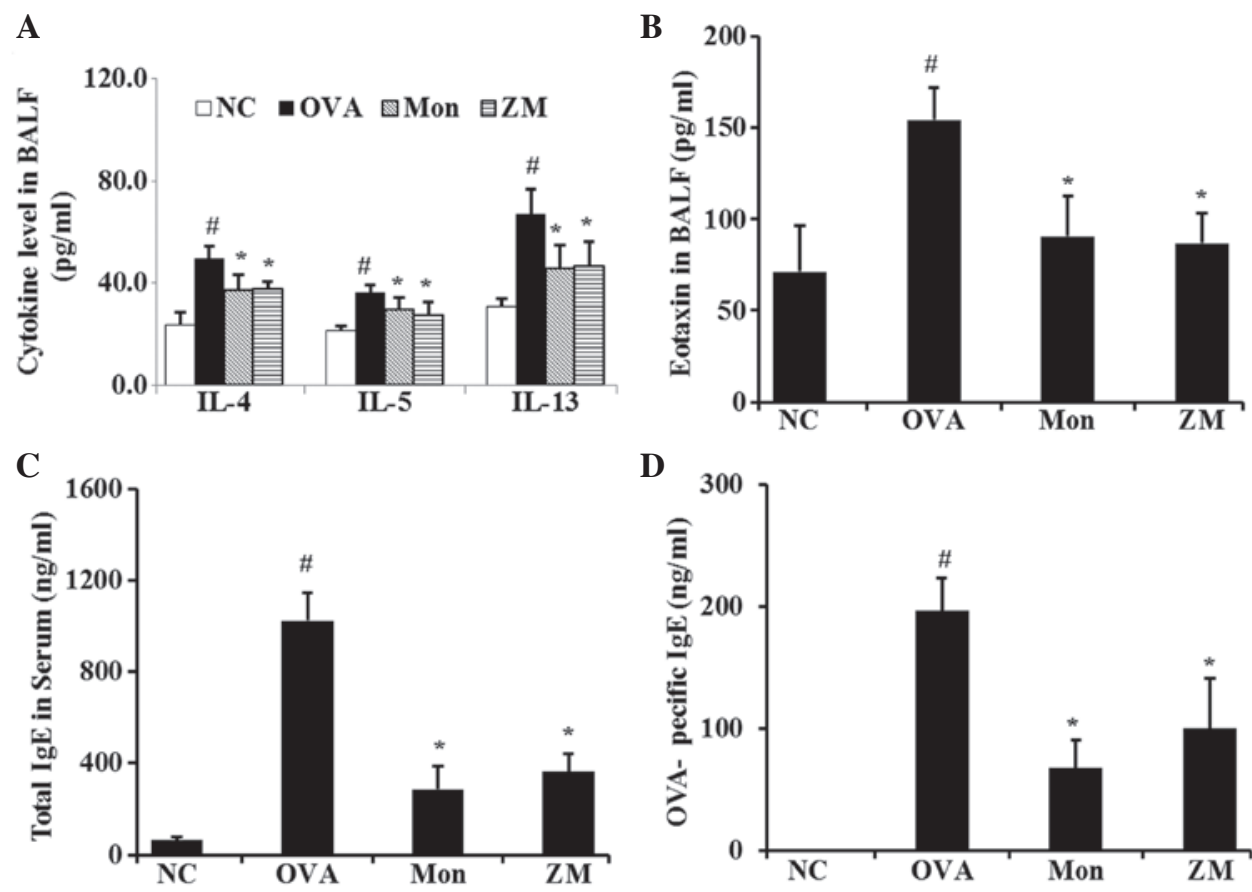

Figure 3. ZM inhibited the levels of pro-inflammatory cytokines, eotaxin and IgE. Levels of (A) pro-inflammatory cytokines in BALF, (B) chemokine in BALF, (C) total IgE in serum and (D) OVA-specific IgE in serum, as determined by ELISA. Data are expressed as the mean \pm standard deviation ( $\mathrm{n}=7 / \mathrm{group}) .{ }^{*} \mathrm{P}<0.05$, compared with NC and " $\mathrm{P}<0.05$, compared with OVA. NC, normal control mice; OVA, ovalbumin-challenged mice; Mon, montelukast ( $30 \mathrm{mg} / \mathrm{kg})+\mathrm{OVA}-\mathrm{challenged}$ mice; ZM, Zingiber mioga (Thunb.) Roscoe (30 mg/kg) + OVA-challenged mice; BALF, bronchoalveolar lavage fluid; IL, interleukin; IgE, immunoglobulin E; $\mathrm{NC}$, normal control.

times with TBST, and then developed using an Enhanced Chemiluminescence kit (Thermo Fisher Scientific).

Lung tissue histopathology. The lung tissue was fixed in $4 \%(\mathrm{v} / \mathrm{v})$ paraformaldehyde, embedded in paraffin, and cut into $4-\mu \mathrm{m}$ sections, prior to staining with hematoxylin and eosin solution (Sigma-Aldrich) and periodic acid-Schiff (IMEB Inc.), in order to detect the inflammation and mucus production of the lung sections, respectively. Tissue sections were mounted and coverslipped. Pathological changes to the lung tissue were examined using a microscope (Leica DM1000; Leica Microsystems, Wetzlar, Germany).
Statistical analysis. Data are expressed as the mean \pm standard deviation. The statistical significance of the results were determined by analysis of variance, followed by a multiple comparison test with Dunnet's adjustment. Statistical analyses were performed using GraphPad InStat v 3.0 (GraphPad, La Jolla, CA, USA). P<0.05 was considered to indicate a statistically significant difference.

\section{Results}

$Z M$ reduces $O V A$-induced $A H R$. The OVA-induced mice exhibited a significant increase in AHR with increasing 

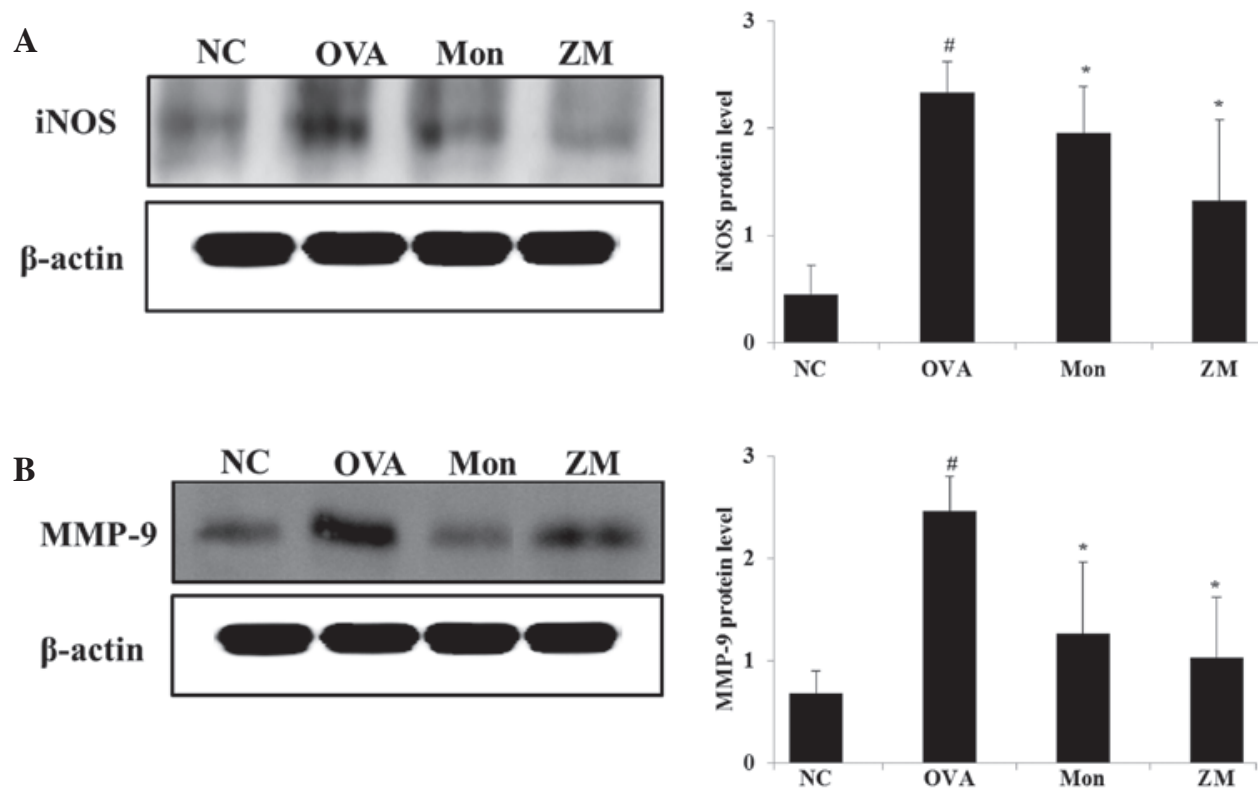

Figure 4. ZM reduced the protein expression levels of iNOS and MMP-9 in the lung tissue. The expression levels of iNOS and MMP-9 were detected by western blot analysis. Detection of $\beta$-actin was conducted in order to confirm the equal loading of proteins. (A) Protein expression levels of iNOS. (B) Protein expression levels of MMP-9. Data are expressed as the mean \pm standard deviation ( $\mathrm{n}=7 /$ group). ${ }^{~} \mathrm{P}<0.05$, compared with $\mathrm{NC}$ and ${ }^{*} \mathrm{P}<0.05$, compared with $\mathrm{OVA}$ NC, normal control mice; OVA, ovalbumin-challenged mice; Mon, montelukast (30 mg/kg) + OVA-challenged mice; ZM, Zingiber mioga (Thunb.) Roscoe $(30 \mathrm{mg} / \mathrm{kg})+$ OVA-challenged mice; iNOS, inducible nitric oxide synthase; MMP-9, matrix metalloproteinase 9.

A

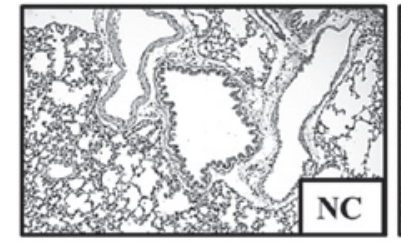

$\mathbf{B}$

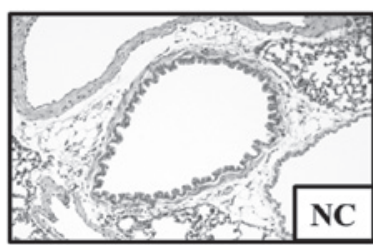

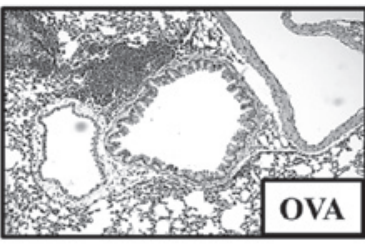
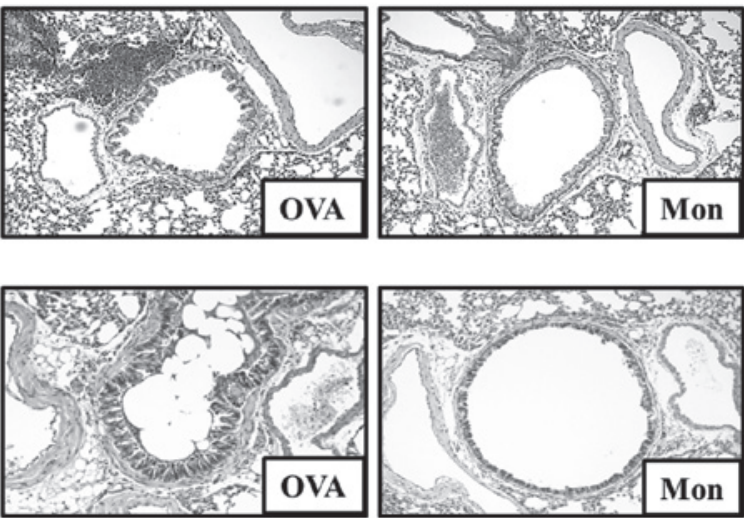
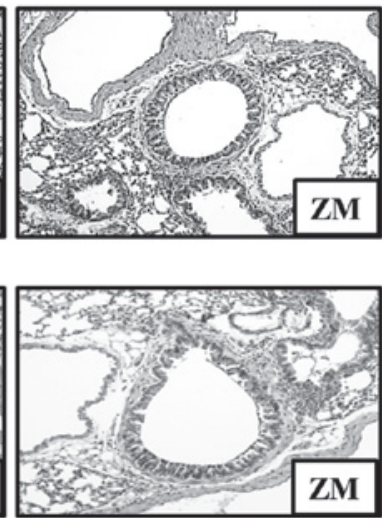

Figure 5. ZM inhibited airway inflammation and mucus production. (A) Histological examination of airway inflammation in lung tissue by hematoxylin and eosin staining. (B) Histological examination of mucus production in the lung tissue by periodic acid-Schiff staining. Magnification, x200. NC, normal control mice; OVA, ovalbumin-challenged mice; Mon, montelukast (30 mg/kg) + OVA-challenged mice; ZM, Zingiber mioga (Thunb.) Roscoe (30 mg/kg) + OVA-challenged mice.

concentrations of methylcholine exposure, compared with the normal control mice. The montelukast-treated mice exhibited significantly reduced AHR, compared with the OVA-induced mice. The ZM-treated mice also exhibited decreased AHR at methylcholine concentrations of 25 and $50 \mathrm{mg} / \mathrm{ml}$, compared with the OVA-challenged mice. These reductions were similar to the results observed in the montelukast-treated mice (Fig. 1).

$Z M$ decreases the number of inflammatory cells in BALF. Significantly increased numbers of inflammatory cells, particularly eosinophils, were observed in the BALF samples from OVA-induced mice compared with samples from the normal controls. BALF samples from the ZM-treated mice exhibited a markedly decreased number of inflammatory cells, including eosinophils, macrophages, lymphocytes and neutrophils, compared with samples from the OVA-challenged mice (Fig. 2).

$Z M$ reduces the levels of proinflammatory cytokines in $B A L F$, and levels of IgE in serum. The levels of IL-4, IL-5, IL-13 and eotaxin were significantly increased in the BALF from OVA-challenged mice, compared with that from the normal controls. However, montelukast-treated mice had significantly reduced levels of these cytokines, as compared with the OVA-challenged mice. The levels of these cytokines were also significantly decreased in the BALF of the ZM-treated mice, compared with that of the OVA-challenged mice (Fig. 3A and B). The total IgE and OVA-specific IgE 
A
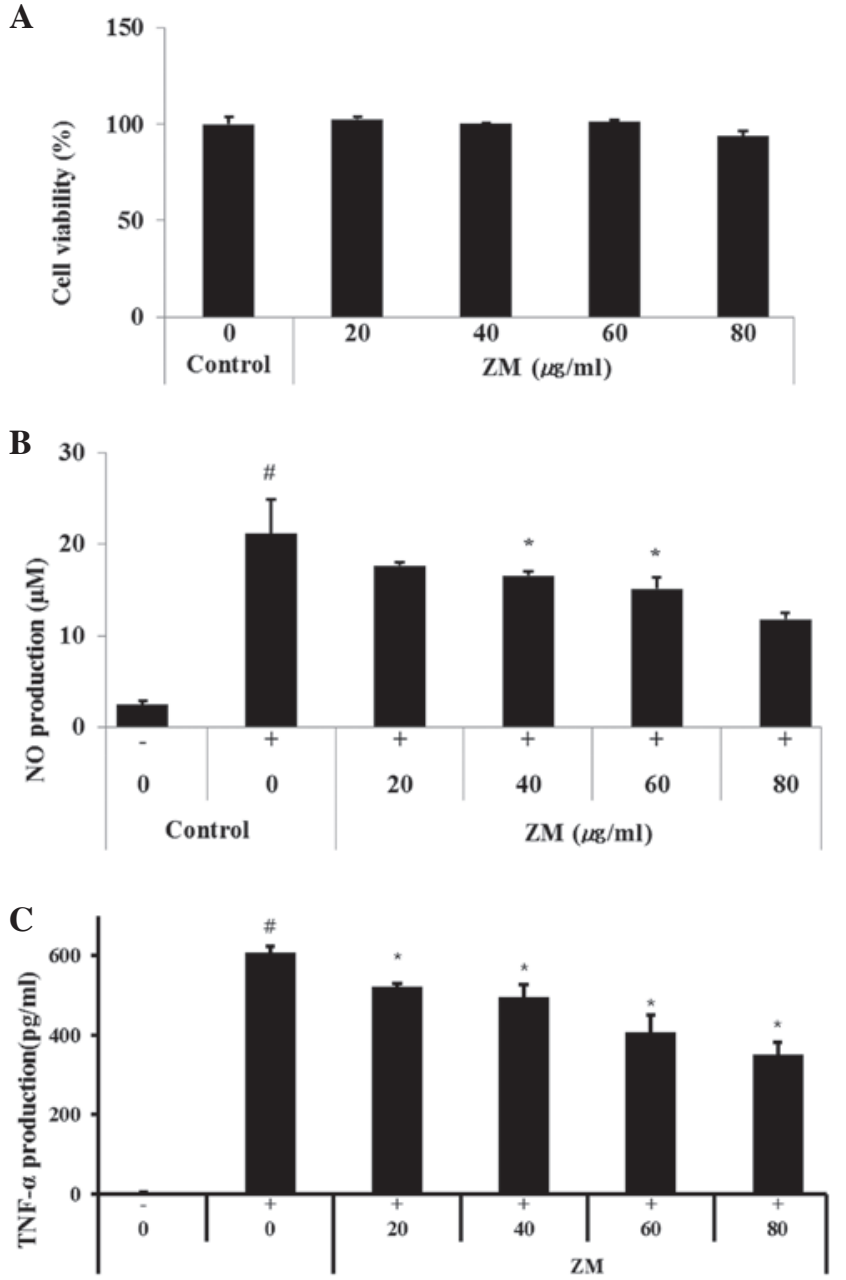

Figure 6. RAW264.7 murine macrophage cells were treated with 20, 40, 60 or $80 \mu \mathrm{g} / \mathrm{ml}$ of ZM for $24 \mathrm{~h}$. (A) Cell survival rates were determined using an MTT assay. ZM inhibited the production of (B) NO and (C) TNF- $\alpha$ in the LPS stimulated RAW264.7 cells. Cells were treated with ZM (20, 40, 60 or $80 \mu \mathrm{g} / \mathrm{ml})$ for $1 \mathrm{~h}$ and with LPS $(0.5 \mu \mathrm{g} / \mathrm{ml})$ for $24 \mathrm{~h}$. Data are expressed as the mean \pm standard deviation. ${ }^{\prime \prime} \mathrm{P}<0.05$, compared with control cells and ${ }^{*} \mathrm{P}<0.05$, compared with LPS-treated cells. ZM, Zingiber mioga (Thunb.) Roscoe; LPS, lipopolysaccharide; $\mathrm{NO}$, nitric oxide; TNF- $\alpha$, tumor necrosis factor- $\alpha$.

serum levels in the OVA-challenged mice were significantly elevated, compared with levels in the normal controls. Conversely, montelukast-treated mice had markedly decreased levels of total and OVA-specific IgE, as compared with the OVA-challenged mice. The ZM-treated mice also exhibited a significant reduction in the total $\mathrm{IgE}$ and OVA-specific $\mathrm{IgE}$ serum levels, compared with those in the OVA-challenged mice (Fig. 3C and D).

ZM inhibits protein expression levels of iNOS and MMP-9 in the lung tissue of OVA-challenged mice. OVA-challenged mice exhibited significantly increased protein expression levels of iNOS in the lung tissue, compared with the normal controls. However, montelukast-treated mice exihibited significantly reduced iNOS expression in lung tissue, as compared with the OVA-challenged mice. In addition, in the ZM-treated mice, a marked reduction in the expression levels of iNOS were detected, as compared with the OVA-challenged mice (Fig. 4A). In the OVA-challenged mice, MMP-9 expression was increased, compared with the normal controls,

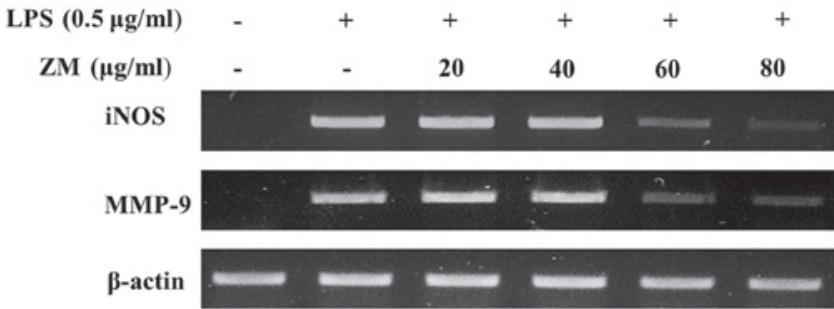

Figure 7. Treatment with ZM reduced the mRNA expression levels of iNOS and MMP-9 in the LPS-stimulated RAW264.7 murine macrophage cells. Detection of $\beta$-actin was conducted in order to confirm the equal loading of mRNA. ZM, Zingiber mioga (Thunb.) Roscoe; LPS, lipopolysaccharide; iNOS, inducible nitric oxide synthase; MMP-9, matrix metalloproteinase 9.

whereas they were significantly decreased in the montelukastand ZM-treated mice, compared with the OVA-challenged mice (Fig. 4B).

ZM decreases inflammatory cell infiltration and mucus production. Lung tissue from the OVA-challenged mice exhibited infiltration of inflammatory cells into the peribronchial and perivascular lesions, and mucus hypersecretion in airway epithelial cells (Fig. 5A and B). However, lung tissue from montelukast-treated mice exhibited a reduction in inflammatory cell infiltration and mucus secretion. In addition, lung tissue from ZM-treated mice exhibited significantly lower inflammatory cell infiltration and mucus secretion, compared with the OVA-challenged mice.

$Z M$ reduces $N O$ production and TNF- $\alpha$ in LPS-stimulated cells. In the present study, nontoxic concentrations of ZM (20, 40, 60 and $80 \mu \mathrm{g} / \mathrm{ml}$; Fig. 6A) were tested for their ability to inhibit LPS-stimulated NO production. The LPS-stimulated cells exhibited increased cellular NO levels, compared with non-stimulated cells. By contrast, the production of NO was inhibited in the cells pre-treated with ZM, in a concentration-dependent manner (Fig. 6B).

As shown in Fig. 6C, the LPS-stimulated cells exhibited markedly increased levels of TNF- $\alpha$, compared with the normal controls, whereas the ZM-treated cells exhibited a significant concentration-dependent decrease in the levels of TNF- $\alpha$, compared with the LPS-stimulated cells.

ZM inhibits iNOS and MMP-9 $m R N A$ expression in LPS-stimulated cells. The LPS-stimulated cells exhibited a significant increase in mRNA expression levels of iNOS, TNF- $\alpha$ and MMP-9, compared with the control group. The LPS-induced mRNA expression levels of iNOS and MMP-9 were significantly reducted in the ZM-treated cells (Fig. 7).

\section{Discussion}

The present study aimed to evaluate the anti-inflammatory effects of ZM in an OVA-induced allergic asthma murine model, and in LPS-stimulated RAW264.7 cells. ZM decreased the number of inflammatory cells, the Th2 cytokine levels and the levels of eotaxin in BALF from mice treated with OVA. In addition, mice treated with $\mathrm{ZM}$ produced significantly reduced serum levels of total and OVA-specific IgE, compared with the 
OVA-challenged mice. ZM also decreased the protein expression levels of iNOS and MMP-9 in the lung tissue, as well as reducing AHR, airway inflammation and mucus production. Furthermore, ZM inhibited the production of NO and TNF- $\alpha$ in the LPS-stimulated RAW264.7 cells, and reduced the mRNA expression levels of iNOS, TNF- $\alpha$ and MMP-9.

Allergic asthma is a chronic inflammatory airway disease that is characterized by persistent AHR, Th2 lymphocyte infiltration and plasma exudation. Allergic asthma is associated with an elevated serum IgE level, eosinophilia and mucus production in the airways $(10,11)$. NO is a particularly important inflammatory mediator of allergic asthma. NO is a gas molecule synthesized by NOS, which is associated with inflammatory responses. It has previously been suggested that iNOS is induced by inflammatory cytokines, such as TNF- $\alpha$, and results in the production of much larger amounts of NO (12). The overproduction of NO underlies pathophysiology of airway inflammation. NO contributes to the infiltration of inflammatory cells, such as neutrophils, monocytes and eosinophils, which produce IL-4, IL-5 and IL-13 Th2 cytokines $(6,13)$. IL-4 promotes B-cell isotype switching and the upregulation of IgE, whereas IL-5 induces the infiltration of eosinophils into the airways (14). IL-13 is also a potent stimulator of airway remodeling, since it induces lung and alveolar enlargement, as well as mucus metaplasia and AHR $(15,16)$. In the present study, Th2 cytokines, including IL-4, IL-5, and IL-13, were markedly decreased in the ZM-treated mice. The ZM-treated mice also exhibited a significant reduction in the number of inflammatory cells, which was accompanied by decreased levels of total and OVA-specific IgE, and eotaxin. Treatment with ZM reduced airway inflammation and mucus production alongside inhibition of iNOS expression in the lung tissue. These findings indicated that ZM may effectively inhibit the development of allergic asthma induced by an OVA challenge. It was hypothesized that this may be associated with the suppression of iNOS expression. In addition, ZM reduced NO and TNF- $\alpha$ production, and iNOS levels in the LPS-stimulated RAW264.7 cells in a concentration-dependent manner.

MMPs are a family of extracellular proteases that are responsible for the degradation of the extracellular matrix during tissue remodeling. Within the MMP family, the MMP-9 gelatinases are specific to the denatured collagens and collagen-IV of the basement membrane (17). MMP-9 is controlled by the inflammatory mediator $\mathrm{NO}$, as well as cytokines and chemokines, and is produced by various types of cells, including inflammatory, endothelial and epithelial cells (18). MMP-9 is associated with airway remodeling and inflammatory cell infiltration into the airways. Previous studies have demonstrated that increased expression levels of MMP-9 in patients with asthma are associated with an increase in the number of inflammatory cells $(19,20)$. Inhibition of MMP-9 has been shown to significantly reduce the production of $\mathrm{Th} 2$ cytokines and $\mathrm{IgE}$, in addition to the expression levels of adhesion molecules, which results in the alleviation of asthmatic responses, such as airway inflammation, mucus overproduction, and AHR (21). Numerous studies have explored novel therapeutic materials focusing on the suppression of MMP-9 expression in asthma $(6,14,17)$. The present study evaluated the protein expression levels of
MMP-9 in lung tissue. ZM-treated mice exhibited reduced MMP-9 expression in lung tissue, compared with the OVA-challenged mice. These findings indicated that ZM may reduce asthmatic responses by downregulating the expression of MMP-9 in lung tissue.

In conclusion, ZM effectively suppressed inflammatory responses in the OVA-challenged mice and LPS-stimulated RAW264.7 cells. Based on these results, the anti-inflammatory effects of ZM were hypothesized to be associated with the suppression of iNOS and MMP-9 expression. The findings suggested that ZM may be a potent therapeutic agent in inflammatory diseases, such as allergic asthma.

\section{Acknowledgements}

The present study was supported by a grant from the KRIBB research Initiative program (grant. no. KGM 1221521) of the Republic of Korea.

\section{References}

1. Shalaby KH, Allard-Coutu A, O'Sullivan MJ, Nakada E, Qureshi ST, Day BJ and Martin JG: Inhaled birch pollen extract induces airway hyperresponsiveness via oxidative stress but independently of pollen-intrinsic NADPH oxidase activity, or the TLR-4-TRIF pathway. J Immunol 191: 922-933, 2013.

2. Prado CM, Martins MA and Tibério IF: Nitric oxide in asthma physiopathology. ISRN Allergy 2011: 832560, 2011.

3. Lee JH, Shon JH, Ryu SY, Hong CS, Moon KD and Park JW: A novel human anti-VCAM-1 monoclonal antibody ameliorates airway inflammation and remodelling. J Cell Mol Med 17: 1271-1281, 2013.

4. Deng Y, Guan M, Xie X, Yang X, Xiang H, Li H, Zou L, Wei J, Wang D and Deng X: Geniposide inhibits airway inflammation and hyperresponsiveness in a mouse model of asthma. Int Immunopharmacol 17: 561-567, 2013.

5. Lee MY, Shin IS, Lim HS and Shin HK: A water extract of Samchulkunbi-tang attenuates airway inflammation by inhibiting inos and MMP-9 activities in an ovalbumin-induced murine asthma model. BMC Complement Altern Med 12: 257, 2012.

6. Shin IS, Lee MY, Lim HS, Ha H, Seo CS, Kim JC and Shin HK: An extract of Crataegus pinnatifida fruit attenuates airway inflammation by modulation of matrix metalloproteinase-9 in ovalbumin induced asthma. PLoS One 7: e45734, 2012.

7. Miyoshi N, Nakamura Y, Ueda Y, Abe M, Ozawa Y, Uchida K and Osawa T: Dietary ginger constituents, galanals A and B, are potent apoptosis inducers in Human T lymphoma Jurkat cells. Cancer Lett 199: 113-119, 2003.

8. Kim HW, Murakami A, Abe M, Ozawa Y, Morimitsu Y, Williams MV and Ohigashi H: Suppressive effects of mioga ginger and ginger constituents on reactive oxygen and nitrogen species generation, and the expression of inducible pro-inflammatory genes in macrophages. Antioxid Redox Signal 7: 1621-1629, 2005.

9. Shin IS, Park JW, Shin NR, Jeon CM, Kwon OK, Lee MY, Kim HS, Kim JC, Oh SR and Ahn KS: Melatonin inhibits MUC5AC production via suppression of MAPK signaling in human airway epithelial cells. J Pineal Res 56: 398-407, 2014.

10. Ra J,Lee S, Kim HJ, Jang YP, Ahn H and Kim J: Bambusae Caulis in Taeniam extract reduces ovalbumin-induced airway inflammation and Thelper 2 responses in mice. J Ethnopharmacol 128: 241-247, 2010.

11. Nader MA, El-Awady MS, Shalaby AA and El-Agamy DS: Sitagliptin exerts anti-inflammatory and anti-allergic effects in ovalbumin-induced murine model of allergic airway disease. Naunyn Schmiedebergs Arch Pharmacol 385: 909-919, 2012.

12. Koarai A, Ichinose M, Sugiura H, Tomaki M, Watanabe M, Yamagata S, Komaki Y, Shirato K and Hattori T: iNOS depletion completely diminishes reactive nitrogen-species formation after an allergic response. Eur Respir J 20: 609-616, 2002.

13. Schmudde I, Laumonnier Y and Köhl J: Anaphylatoxins coordinate innate and adaptive immune responses in allergic asthma. Semin Immunol 25: 2-11, 2013. 
14. Shin IS, Hong J, Jeon CM, Shin NR, Kwon OK, Kim HS, Kim JC, Oh SR and Ahn KS: Diallyl-disulfide, an organosulfur compound of garlic, attenuates airway inflammation via activation of the Nrf-2/HO-1 pathway and NF-kappaB suppression. Food Chem Toxicol 62: 506-513, 2013.

15. Simoes DC, Xanthou G, Petrochilou K, Panoutsakopoulou V, Roussos C and Gratziou C: Osteopontin deficiency protects against airway remodeling and hyperresponsiveness in chronic asthma. Am J Respir Crit Care Med 179: 894-902, 2009.

16. Shen JJ, Chiang MS, Kuo Ml, Leu YL, Hwang TL, Liou CJ and Huang WC: Partially purified extract and viscolin from Viscum coloratum attenuate airway inflammation and eosinophil infiltration in ovalbumin-sensitized mice. J Ethnopharmacol 135: 646-653, 2011.

17. Hsu CH, Hu CM, Lu KH, Yang SF, Tsai CH, Ko CL, Sun HL and Lue KH: Effect of selective cysteinyl leukotriene receptor antagonists on airway inflammation and matrix metalloproteinase expression in a mouse asthma model. Pediatr Neonatol 53 235-244, 2012.
18. Oh YC, Cho WK, Jeong YH, Im GY, Kim A, Hwang YH, Kim T, Song KH and Ma JY: A novel herbal medicine KIOM-MA exerts an anti-inflammatory effect in LPS-stimulated RAW 264.7 macrophage cells. Evid Based Complement Alternat Med 2012: $462383,2012$.

19. Gueders MM, Foidart JM, Noel A and Cataldo DD: Matrix metalloproteinases (MMPs) and tissue inhibitors of MMPs in the respiratory tract: Potential implications in asthma and other lung diseases. Eur J Pharmacol 533: 133-144, 2006.

20. Ventura I, Vega A, Chacón P, Chamorro C, Aroca R, Gómez E, Bellido V, Peunte Y, Blanca M and Monteseirin J: Neutrophils from allergic asthmatic patients produce and release metalloproteinase- 9 upon direct exposure to allergens. Allergy 69: 898-905, 2014.

21. Lee KS, Jin SM, Kim HJ and Lee YC: Matrix metalloproteinase inhibitor regulates inflammatory cell migration by reducing ICAM-1 and VCAM-1 expression in a murine model of toluene diisocyanate-induced asthma. J Allergy Clin Immunol 111: 1278-1284, 2003. 